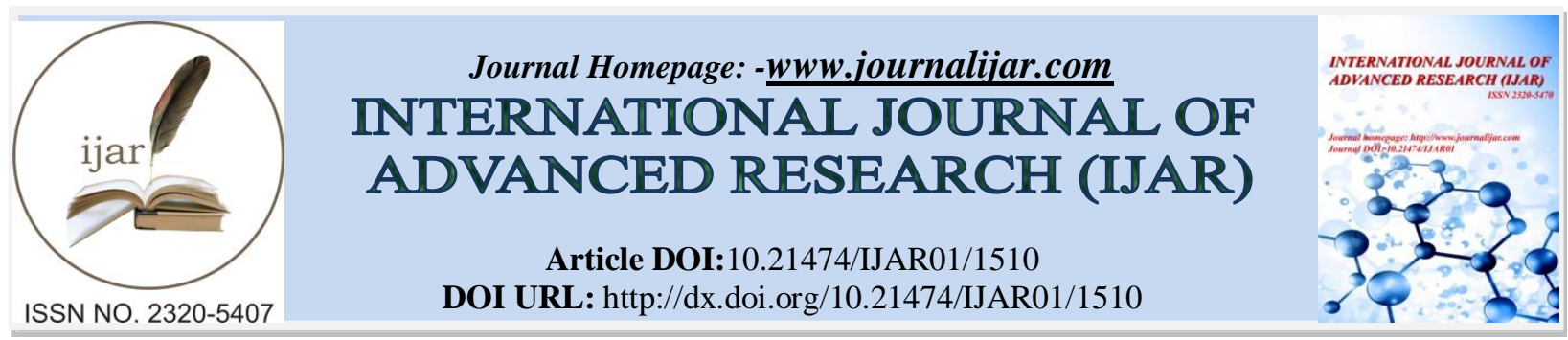

RESEARCH ARTICLE

\title{
MOLECULAR DETECTION OF ANTIBIOTIC RESISTANCE GENE (MECA) IN STAPHYLOCOCCUS EPIDERMIDIS LOCAL ISOLATES.
}

Rusul Muzher Hussein and Marrib Nazih Rasheed.

Ministry of Higher Education and Scientific Research- University of Baghdad - Genetic Engineering and Biotechnology Institute for Postgraduate Studies. Iraq-Baghdad.

\section{Manuscript Info}

Manuscript History

Received: 16 July 2016

Final Accepted: 19 August 2016

Published: September 2016

Key words:-

Staphylococcus epidermidis, antibiotic resistance gene $(m e c A)$, polymerase chain reaction.

\section{Abstract}

The mecAgene is a gene found in bacterial cells. The mecAgene allows a bacterium to be resistant to antibiotics such as methicillin, penicillin and other antibiotics. This study is based on the molecular analysis of the antibiotic resistance gene (mecA). The polymorphism of the $m e c A g e n e$ existing in different $S$. epidermidishave been analyzed in this study. Seventy five isolates (57) of S.epidermidiswere obtained from eighty four (84) which were collected three hospitals in Baghdad include Al-Yarmuk General Teaching Hospital , Al-Karama teaching hospital, Ibn-ALbalady teaching hospital. These isolates were collected from clinical sources the samples included, wound swab, burn swab, ear swab and urine. .DNA from each sample was isolated and the mecAgene was amplified with appropriate primers. The PCR results of 57 mecA gene positive S.epidermidisgave the band size of amplicons about 500pb. The presence of mecAgene seems to be enhanced in biofilm producers and enable S.epidermidis strains to show increasing resistance to different groups of antibiotics.

Copy Right, IJAR, 2016,. All rights reserved.

\section{Introduction:-}

$S$. epidermidis which is known as a natural colonizer of healthy human skin and mucosa, is also a common nosocomial pathogen along with other Coagulase Negative Staphylococci (CONS)[1].S. epidermidis is the most important pathogen, responsible from many indwelling medical device related infections such as; catheter, prosthetic joint, vascular graft, surgical site, central nervous system shunt and cardiac device related ones. Therefore, $S$. epidermidis strains especially emerge as life-threatening pathogens triggering septicemia, meningitis and other serious conditions in medical device using and immunocomprised patient [2, 3, 4, 5]. One of the most important mechanisms making these commensal inhabitants dangerous for medical device using and immunocomprised patients is known as biofilm formation. By means of having ability to adhere to various surfaces and form slimy layer known as biofilm on them[6, 7, 8,9]. Biofilm is believed to make clinical S.epidermidis strains more resistant to administered antibiotics and to host defense mechanisms and highly contributed to cause nosocomial infections(NI) in patients [10].

In clinical practice, S. epidermidishas become one of the most significant species among methicillin-resistant coagulase negative staphylococci (CONS). There are various scientific world reports that stated that approximately between $80 \%$ and $90 \%$ of S. epidermidis strains isolated from patients with nosocomial infections(NI )carried the 
mecAgene $[11,12]$. The presence of mecA gene seems to be enhanced in biofilm producers and enable $S$. epidermidis strains to show increasing resistance to different groups of antibiotics [13, 14].

The mecAgene is a component of a large DNA fragment designated as mecDNA, Theacquisition of mecDNA is considered to be the first genetic requisite for methicillin resistance in staphylococci [15].The aim of this study was to detect the presence ofmecA gene in S. epidermidis from clinical sources by PCR amplification.

\section{Material and method:-}

\section{Sample collection:-}

Fifty seven isolates were obtained from 84 samples taken from clinical sources which were collected from three hospitals in Baghdad include Al-Yarmuk General Teaching Hospital, Al-Karama teaching hospital, Ibn-ALbalady teaching hospital. These sample include (wound swab,ear swab,burn swab and urine). All samples were cultured on blood agar and incubated at $37^{\circ} \mathrm{C}$ for 24 hours. And then on differential media manittol salt agar S.epidermidis is not color change.

All the isolates were identified on the basis of colony morphology, biochemical test catalaseand coagulase test. Then identifiedusing a commercial biotyping system (api STAPH, bioMerieux, Inc., Hazelwood, MO) [16, 17, 18].

The strains were stored in brain heart Infusion

(BHI) broth with $20 \%$ of glycerol at $-20^{\circ} \mathrm{C}$. The working cultures of the isolates were prepared in $\mathrm{BHI}$ broth at $37^{\circ} \mathrm{C}$ for $18 \mathrm{~h}$. Chromosomal DNA from the $S$. epidermidisstrains isolated from different samples was extracted

\section{Antibiotic Susceptibility Test:-}

The Kirby-Bauer's disc diffusion method using methicillin $5 \mu \mathrm{g}$ disc on Muller-Hinton agar incubated overnight at $37^{\circ} \mathrm{C}$ was done for the detection of methicillin-resistant strains of S. epidermidis according to the zone that form around antibiotic disc.

\section{DNA extraction:-}

DNA extraction using Genomic DNA extraction Kit, concentration and purity were determined using Nano drop 1000 spectrophotometer at 260/280nm.

\section{mecAgene Detection:-}

Staphylococcus epidermidisisolates were investigated for the presence of antibiotic resistance gene (mecA). The PCR for amplification of mecAgene was performed in a total reaction volume of $20 \mu \mathrm{l}$ for one sample. The sequence of primer used for amplification of mecAgene forward 5-AAAATCGATGGTAAAGGTTGGC-3, Reverse 5CGTGTTTTCAACATTTAATGCAA-3 the band size (500pb). The PCR cycling protocol was applied as following: initial denaturation at $94^{\circ} \mathrm{C}$ for $3 \mathrm{~min}$, followed by 30 cycles of denaturation at $94^{\circ} \mathrm{C}$ for 30 second, annealing at $55^{\circ} \mathrm{C}$ for 30 second and extension at $72^{\circ} \mathrm{C}$ for 30 second, followed by a final extension at $72^{\circ} \mathrm{C}$ for $10 \mathrm{~min}$. Agarose Gel Electrophoresis and Visualization of PCR Products: $5 \mu$ of each amplicon was electrophoresed in $2 \%$ agarose gel.

\section{Results and Discussion:-}

A total number of 57 isolates were obtained from 84 samples collected from clinical sources included wound swab, burn swab, ear swab and urine. All samples were cultured on blood agar and incubated at $37^{\circ} \mathrm{C}$ for 24 hours. According to the preliminary results, table [1] showed the ratio of sample contain mecA gene of S.epidermidis from clinical sources.

Table 1:- The sample collection and ratio of mecAgene contain.

\begin{tabular}{|l|l|l|}
\hline Sample source & Ratio of sample collected & Ratio of mecA \\
\hline wound & 42 & 34 \\
\hline Ear swab & 30 & 15 \\
\hline Urine & 9 & 8 \\
\hline Burn & 3 & 0 \\
\hline Total & 84 & $57 \%$ \\
\hline
\end{tabular}


The results it is reported that from (105) clinical sample isolates (84) isolates were Staphylococcus epidermidis. Several biochemical tests were carried out to identify the S. epidermidis. All Gram-positive isolates gave positive results in the Catalase tests. The positive reaction indicated the liberation of free oxygen as gas bubbles after mixing of hydrogen peroxide solution with a little amount of bacterial growth [19]. In order to support the previous biochemical test, coagulase-negativeand detect the ability produce of biofilm by growth on Congo-red agarbiofilm producers form black colonies on CRA, whereas non-producers form red colonies [20]. The results revealed that from all 84 isolates, it was obtained $62(73.8 \%)$ showed resistant to the Methicillin while $22(26.2 \%)$ were sensitive to the Methicillin (inhibition zone of $23 \mathrm{~mm}$ or less by Kirby-Bauer's disc diffusion method using $5 \mu \mathrm{g}$ methicillin disc on Mueller-Hinton agar).This result agreed with the study by (Martinset al., 2013) which found $73.8 \%$ of $S$. epidermidis isolates were resistant to methicillin by disc diffusion method[21].

PCR results indicated that seventy five 57(61.2\%) isolates were positive for mecAgenes as indicated by $500 \mathrm{bp}$

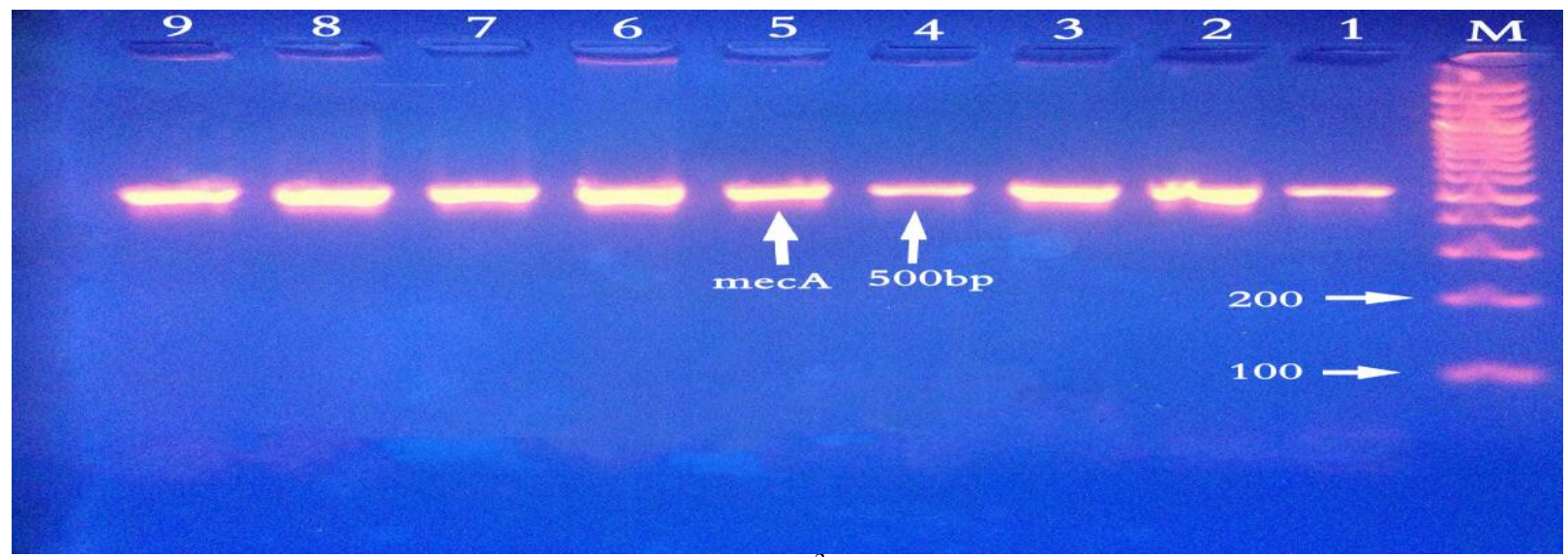

Figure 1:- Agarose gel electrophoresis (2\%agarose, $\left.5 \mathrm{~V} / \mathrm{cm}^{2}\right)$ PCR results with primer for mecAgene M: Molecular size marker; lane 1-9 (500 bp) band obtained with DNA from mecAgene.

Whereas 27 (38.8\%)mecAgene negative. The result that obtain by PCR of the of S. epidermidis isolate agree with our study by (Contreras et al., 2013) it was found $64 \%$ of the S. epidermidis isolated resistance to methicillin and carried themecAgene[22].Genotypic methods are more accurate in detecting methicillin resistant Staphylococci as compared to conventional susceptibility methods. In addition, several culture conditions can also influence methicillin resistance such as the temperature, $\mathrm{pH}$ and concentration of $\mathrm{NaCl}$ in the medium[23]. Strains with low resistance level are usually complicated by these factors and impair the process of detection. The greatest disadvantage of phenotypic methods is that it is time-consuming [24]. And sometimes difficult to detect some strains; PCR can produce results within 24 hours as compared to the conventional methods which requires at least 48 hours there for the molecular detection methods are more preferred, favorable and accurate than the phenotypic method [25]. The study results indicate that $61.2 \%$ of the 57 methicillin-resistant strains of $S$. epidermidis samples were mecAgene positive. Whereas 27(38.8) \% samples as mecA negative by PCR method. However, the reason for the of the mecA negativity can be attributed to one of the following:

1. Differing levels of $m e c A$ gene expression of methicillin resistance, occurring every 104 or 106 cells [26].

2. Absence of penicillinase plasmid, which otherwise plays an important role in the stability and phenotypic expression of the mecA gene [27]. 


\section{References:-}

1. Otto, M. (2009). Staphylococcus epidermidis - the 'accidental' pathogen. Nat Rev Microbiol. 7:555-567.

2. Goldman, M.;Delage, G.; Beauregard, P.;Pruneau-Fortier D.,Ismaïl, J. and Robillard P. (2001).A fatal case of transfusion-transmitted Staphylococcus epidermidis sepsis. Transfusion. 41:1075-1076.

3. Guiot, H.;Visser, L.; Barge, R.; Bosboom, R. and van de Klundert, J. (1994). Fatal meningitis due to catheterrelated Staphylococcus epidermidisbacteraemia in a granulocytopenic patient without predisposing trauma. Eur J ClinMicrobiol Infect Dis. 1994; 13(9):772-773.

4. Poutsiaka, D. ; Price, L. ; Ucuzian, A. ; Chan ,G .; Miller, K. and Snydman, D.(2007). Blood stream infection after hematopoietic stem cell transplantation is associated with increased mortality. Bone Marrow Transplant , 40:63-70

5. Ziebuhr,W.;Hennig, S.;Eckart,M.;Krenzler, H.;Batzilla, C. and Kozitskaya S. (2006). Nosocomial infections by Staphylococcus epidermidis: how a commensal bacterium turns into a pathogen. Int J AntimicrobAgents; 28:14-20.

6. Casterton, J. ; Lewandowski, Z.;Caldwell, D.;Korber, D. and Lappin-Scott H. (1995).Microbial biofilms. Annu Rev Microbiol; 49:711-745.

7. Shiro, H. ; Muller, E. ; Gutierrez, N. ; Boisot, S. ; Grout, M. ; Tosteson, T. Goldmann D. and Pier G. (1994). Transposon mutants of Staphylococcus epidermidis deficient in elaboration of capsular polysaccharide/adhesin and slime are avirulent in a rabbit model of endocarditis. J Infect Dis; 169(5):10421049.

8. Tunney, M. ; Patrick, S. ; Gorman, S. ; Nixon, J. ; Anderson, N. ; Davis , R. ; Hanna ,D. and Ramage , G. (1998) . Improved detection of infection in hip replacements: a currently underestimated problem. J Bone Joint Surg; 80B:568-572.

9. Cabrera-Contreras; Morelos-Ramírez; Galicia-Camacho, and Meléndez-Herrada. (2010). "Antibiotic susceptibility and biofilm production and correlation to methicillin resistant genotype of Staphylococcus epidermidis strains from Mexican hospital," in Proceedings of the 110th General Meeting of the American Society for Microbiology (ASM' 10), pp. 23-27, San Diego, Calif, USA, Abstract L-219.

10. Rupp and Archer. (1994). "Coagulase-negative staphylococci: pathogens associated with medical progress," Clinical Infectious Diseases, vol. 19, no. 2, pp. 231-245. .

11. Urdez-Hernández; Sifuentes-Osornio; Calva, and Villalobos-Zapata. (1999). "Epidemiological and biological characteristics of methicillin-resistant staphylococcal infections in a Mexican hospital," Archives of Medical Research, vol. 30, no. 4, pp. 325-331.

12. Mack; Saboteur; Dubinsky; Rohde; Horstkotte, and Knoblauch. (2002). "Differential expression of methicillin resistance by different biofilm-negative Staphylococcus epidermidis transposon mutant classes," Antimicrobial Agents and Chemotherapy, vol. 46, no. 1, pp. 178-183.

13. Kozitskaya ; Cho ; Dietrich ; Marre ; Naber, and Ziebuhr. (2004). "The bacterial insertion sequence element IS256 occurs preferentially in nosocomial Staphylococcus epidermidis isolates: association with biofilm formation and resistance to aminoglycosides," Infection and Immunity, vol. 72, no. 2, pp. 1210-1215. .

14. Nobumichi, K.; Koki, T. and Shozo, U. (1998).Analysis of diversity of mutations in the mecIgene and mecApromoter/operator region of methicillin-resistant Staphylococcus aureus and Staphylococcus epidermidis. Antimicrob Agents Chemother,42: (3) 717-720

15. Moyes, R.; Reynolds, J. and Breakwel, D. (2009). Diferential staining of bacteria: gram stain. Cur. Protoc. Microbi.

16. Turkyilmaz, S. and Kaya, O. (2006). Determination of some virulence factors in Staphylococcus spp. isolated from various clinical samples. Turkish Journal of Veterinary Animal Science. 30: $127-132$.

17. Nneoma, C.; Jean, S. and Walter, C. (2013).Conventional and Rapid Methods for Identification of Staphylococcus aureus from Clinical Specimens. American Journal of Biomedical and Life Sciences., 1(3): 4143

18. Brooks, G..; Carroll, K.; Butel, J. and Morse,S.(2007). (Jawetz) Melnick and Adelbergs Medical Microbiology, 24 th .ed. The McGraw-Hill Companies, Inc., New York, 224-232.

19. Jain A and Agarwal A. (2008). Biofilm production, a marker of pathogenic potential of colonizing and commensal staphylococci. J Microbiol Methods. 2009, 76: 88-92. 10.1016/j.mimet.2008.09.017

20. Martins,A . ;Riboli ,D. ; Camargo ,C. ; Pereira ,V. ;Sampaio ,R . And Cunha,M. (2013). Antimicrobial resistance and persistence of Staphylococcus epidermidis clones in a Brazilian university hospital.Diagnostic Microbiology and Infectious Disease;Volume 77; Pages 164-168. 
21. Contreras, R.; Ramírez, R.; Camacho,A.; and Herrada, E.(2013). Antibiotic Resistance and Biofilm Production in Staphylococcus epidermidis Strains, Isolated from a Tertiary Care Hospital in Mexico City. ID 918921, 5 pages

22. Murakami K. ; Minamide W. ; Wada K. ; Nakamura E. ; Teraoka H. and Watanabe S. (1991).Identification of Methicillin-resistant Strains of Staphylococci by polymerase chain reaction. J ClinMicrobiol ; 29: 2240-2244.

23. Sabath L. (1982). Mechanisms of resistance to beta lactumantibitics in strains of Staphylococcus aureus. Ann. Intern. Med; 97: 339-344.

24. Kalhor H.;Sharuati L.;Validi M.;Tabatabaiefar M. and Nafisi M. (2012). Comparison of Agar Screen and duplex-PCR methods in determination of methicillin-resistant Staphylococcus aureus (MRSA) strains isolated from nasal carriage. African Journal of Microbiology Research. 3722-3726.

25. Al Salihy S. and James A. (1972). Loss of methicillin resistance from resistant strains of Staphylococcus aureus. Lancet. 331-332.

26. Hiramatsu K.; Suzuki E.; Takayama H.; Katayama Y. and Yokota T. (1990). Role of penicillinase plasmids in the stability of the mecA gene in methicillin - resistant Staphylococcus aureus. Antimicrob. Agents. Chemother. 34: 600-604. 